\title{
Efeito da temperatura no crescimento micelial, produção e germinação de conídios de Colletotrichum gloeosporioides, isolados de frutos de palmeira juçara (Euterpe edulis Mart)
}

\author{
Tathianne Pastana de Sousa Poltronieri ${ }^{1}$, Luís Antônio Siqueira de Azevedoํㅜ , Diene Elen Miranda da Silva ${ }^{1}$.
}

\author{
${ }^{1}$ Departamento de Fitopatologia e Entomologia, Instituto de Biologia, Universidade Federal Rural do Rio de Janeiro, CEP 23890-000, Rio de \\ Janeiro, Seropédica, RJ. 2012. \\ Autor para correspondência: Tathianne Pastana de Sousa Poltronieri (tathianne_pastana@ hotmail.com) \\ Data de chegada: 01/11/2012. Aceito para publicação em: 01/10/2013.
}

1857

\section{RESUMO}

Poltronieri, T.P.S.; Azevedo, L.A.S.; Silva, D.E.M. Efeito da temperatura no crescimento micelial, produção e germinação de conídios de Colletotrichum gloeosporioides, isolados de frutos de palmeira juçara (Euterpe edulis Mart). Summa Phytopathologica, v.39, n.4, p.281-285, 2013.

A palmeira juçara (Euterpe edulis) é uma das espécies mais importantes da Mata Atlântica. E. edulis faz parte da lista das espécies florestais ameaçadas de extinção. A antracnose, causada por Colletotrichum gloeosporioides, é a principal doença do fruto da juçara. O patógeno prejudica a germinação das sementes e pode causar perda total da produção da polpa do fruto. O objetivo deste trabalho foi avaliar a influência da temperatura no desenvolvimento de quatro isolados de C. gloeosporioides obtidos de frutos de juçara. Os isolados foram obtidos de frutos doentes da região de Paraty-RJ e Ubatuba-SP. Dos isolamentos monospóricos de C. gloeosporioides, discos de micélio com $7 \mathrm{~mm}$ de diâmetro foram transferidos para placas de
Petri contendo meio BDA e submetidos às temperaturas de $20^{\circ}, 25^{\circ}$, $28^{\circ}, 32^{\circ}$ e $35^{\circ} \mathrm{C}$ durante sete dias sob fotoperíodo de 12 horas em câmara tipo BOD. Foram avaliados as variáveis: crescimento micelial diariamente por meio de medições ortogonais na placa, produção e germinação de conídios aos sete dias de idade (inoculação). A maior taxa de crescimento micelial de C. gloeosporioides ocorreu aos $28^{\circ} \mathrm{C}$, seguida pela temperatura de $25^{\circ} \mathrm{C}$. A produção de conídios foi maior a $28^{\circ} \mathrm{C}$, seguida na temperatura de $30^{\circ} \mathrm{C}$. A germinação de conídios foi maior a $28^{\circ} \mathrm{C}$ atingindo $84 \%$ a $87 \%$. Concluiu-se que o crescimento micelial, a produção e germinação dos conídios dos isolados de $C$. gloeosporioides é maior na temperatura de $28^{\circ} \mathrm{C}$.

Palavras-chave adicionais: Antracnose, Palmeira Açaí, Palmito, Mata Atlântica, multiplicação in vitro

\section{ABSTRACT}

Poltronieri, T.P.S.; Azevedo, L.A.S.; Silva, D.E.M. Effect of temperature on mycelial growth and conidial production and germination for Colletotrichum gloeosporioides isolated from juçara palm fruits (Euterpe edulis Mart). Summa Phytopathologica, v.39, n.4, p.281-285, 2013.

Juçara palm tree (Euterpe edulis) is one of the most important species in the Atlantic Forest. E. edulis is in the list of endangered forest species. Anthracnose, caused by $C$. gloeosporioides, is the major disease of juçara fruit. This pathogen affects seed germination and can cause total loss of fruit pulp production. The aim of this study was to evaluate the influence of temperature on the development of four Colletotrichum gloeosporioides isolates from juçara fruits. The isolates were obtained from diseased fruits from the region of Paraty-Rio de Janeiro State and Ubatuba-São Paulo State, Brazil. From C. gloeosporioides monosporic isolates, $7 \mathrm{~mm}$-diameter mycelial discs were transferred to Petri dishes containing PDA medium and subjected to the temperatures of $20^{\circ}, 25^{\circ}, 28^{\circ}, 32^{\circ}$ and $35^{\circ} \mathrm{C}$ for seven days at 12 -h photoperiod in a BOD chamber. The following variables were evaluated: mycelial growth by daily measuring the orthogonal plate, conidial production and germination at seven days of age (inoculation). The highest $C$. gloeosporioides mycelial growth rate occurred at $28^{\circ} \mathrm{C}$, followed by $25^{\circ} \mathrm{C}$. Conidial production was higher at $28^{\circ} \mathrm{C}$, then at $30^{\circ} \mathrm{C}$. Conidial germination was higher at $28^{\circ} \mathrm{C}$, reaching $84 \%$ to $87 \%$. It was concluded that the mycelial growth and the conidial production and germination for C. gloeosporioides isolates is high at the temperature of $28^{\circ} \mathrm{C}$.

Additional keywords: Anthracnose, Acai Palm, heart of palm, Atlantic Forest, in vitro multiplication

A juçara (Euterpe edulis Mart.), é uma palmeira típica da Floresta Atlântica, tendo ocorrência em vasta extensão territorial, desde o sul da Bahia até Rio Grande do Sul. A Palmeira produz palmito de excelente qualidade, porém a exploração extrativista reduziu a população da espécie nas reservas naturais (16)

Os contínuos trabalhos buscando a retirada da palmeira juçara da lista das espécies ameaçadas de extinção mostram o grande potencial dos frutos desta palmeira, pois o manejo dos frutos da juçara para 
obtenção da polpa alimentar, com alto potencial nutricional, semelhante ao açaí (E. oleracea), produzido na Amazônia e de sementes pode ser considerado como uma importante estratégia de conservação desta espécie e das florestas nativas, além do potencial socioeconômico da segurança alimentar e geração de renda das comunidades caiçaras na Mata Atlântica (7).

A utilização dos frutos de juçara, ao contrário do que ocorre com o palmito não necessita da derrubada da árvore, que leva de cinco a oito anos para chegar ao estágio de corte. A coleta dos frutos pode ser realizada ano após ano na mesma palmeira e representa uma alternativa para a conservação da espécie e para o equilíbrio da cadeia alimentar da Mata Atlântica, visto que vários animais se nutrem deles (4).

Contudo, recentemente foi relatada a ocorrência de antracnose em seus frutos, sendo capaz de reduzir drasticamente a produção a partir do segundo ano de plantio e inibir a germinação das sementes (14).

A identificação do fungo Colletotrichum sp. causando a antracnose como principal doença da palmeira juçara na região da Mata Atlântica, gerou a necessidade de busca de alternativas que visem à comprovação do seu potencial patogênico e seu controle. Dessa forma, torna-se necessário estudar melhor o patógeno, a interação patógeno-hospedeiro e as condições edafoclimaticas que predispõem a planta ao patógeno (10).

O conhecimento dos efeitos do ambiente no desenvolvimento de patógenos pode auxiliar nas estratégias de manejo de doenças. A temperatura influência tanto o crescimento micelial, a esporulação, a germinação de conídios e na coloração das colônias, podendo ser utilizada como parâmetro para diferenciação de espécies (12).

Informações sobre os fatores ambientais são valiosas no desenvolvimento de sistemas de prevenção de doenças e podem contribuir para definir ações de controle (17). As informaçoes sobre a etiologia do patossistema Colletotrichum sp.-juçara ainda são bastante escassas.

O objetivo do presente trabalho foi avaliar o efeito da temperatura no crescimento micelial, produção e germinação de conídios de $C$. gloeosporioides isolados dos frutos da palmeira juçara.

O estudo foi realizado a partir de amostras de frutos de juçara, doentes, coletados nos municípios de Paraty-RJ e Ubatuba-SP, litoral sul do estado do Rio de Janeiro e litoral norte do estado de São Paulo, regiões sob domínio de floresta ombrófila densa. Os isolados de $C$. gloeosporioides, são provenientes de quatro locais diferentes de coleta, sendo eles: Camburi, Corcovado, Praia Almada e Praia Brava.

O clima da região, segundo a classificação de Koeppen, é considerado como tropical úmido. A precipitação média anual em Ubatuba é de $2154,2 \mathrm{~mm}$, sendo a temperatura média no mês mais frio de $19^{\circ} \mathrm{C}$ (julho) e no mês mais quente de $26^{\circ} \mathrm{C}$ (janeiro) (2). Em Paraty a precipitação média é de $750 \mathrm{~mm}$ por ano, e a temperatura média do mês mais frio é de $12^{\circ} \mathrm{C}$ e no mês mais quente de $38^{\circ} \mathrm{C}$ (7).

Durante o período de floração e frutificação de juçara, que vai de fevereiro até julho e de setembro até novembro, foram realizadas coletas de frutos em diferentes estádios de maturação, nos anos de 2011 e 2012. As coletas foram realizadas em plantas que apresentavam frutos com sintomas típicos da doença, em quatro diferentes locais, sendo também coletados frutos sem sintomas. As amostras foram identificadas e transportadas para análise no Laboratório de Fitopatologia, pertencente ao Instituto de Biologia, onde se localiza o Departamento de Fitopatologia e Entomologia da Universidade Federal Rural do Rio de Janeiro (UFRRJ).

A coleta dos cachos foi realizada com o auxílio de peconha para escalada na planta, sendo coletados seis cachos, sendo: quatro provenientes de plantas com fruto visivelmente sintomáticos e dois provenientes de plantas com frutos aparentemente sadios. Foi coletado um cacho por planta.

Para isolamento indireto do patógeno, os frutos de juçara apresentando sintomas de antracnose, foram lavados com água corrente e sabão, posteriormente enxutos com papel toalha. Foram então retirados fragmentos da área de transição da lesão, desinfestados com álcool a $70 \%$ por 30 segundos, em seguida transferidos para placas de Petri contendo hipoclorito de sódio a 1,5\% por 2 minutos e lavados duas vezes em água destilada e esterilizada, para retirada do excesso de hipoclorito. A seguir, os fragmentos foram transferidos para as placas de Petri de plástico contendo meio de cultura Batata Dextrose Ágar (BDA sintético). As placas de Petri foram incubadas em câmaras de crescimento (BOD) a $25^{\circ} \mathrm{C}$ por 10 dias. Após as colônias terem desenvolvido fragmento de micélio, foram repicados e armazenados em tubos de ensaio com BDA. Após incubação por sete dias em câmaras de crescimento a $25^{\circ} \mathrm{C}$, foram feitas suspensões de conídios que foram riscadas em placas com meio BDA com o objetivo de se obter culturas de isolados monospóricos.

Os discos de micélio dos quatro isolados de C. gloeosporioides com $7 \mathrm{~mm}$ de diâmetro com meio de cultura BDA foram transferidos para placas de Petri contendo aproximadamente $20 \mathrm{~mL}$ de meio BDA. As placas foram submetidas a incubação com temperatura de $20^{\circ} ; 25^{\circ}$; $28^{\circ} ; 30^{\circ} ; 32^{\circ}$ e $35^{\circ} \mathrm{C}$, sob fotoperíodo de $12 \mathrm{~h}$, durante sete dias em BOD.

A avaliação do crescimento micelial foi feita pela medição, a cada 24 h, registrando-se o diâmetro em milímetros das colônias, em posição ortogonal, durante sete dias, a partir do momento em que foram colocados os discos de micélio contendo o isolado. Os dados foram utilizados no cálculo do índice de velocidade de crescimento micelial, conforme a fórmula descrita por Oliveira (13):

$$
\begin{gathered}
\mathrm{IVCM}=\sum(\mathrm{D}-\mathrm{Da}) \\
\mathrm{N}
\end{gathered}
$$

Sendo:

IVCM= índice de velocidade de crescimento micelial;

$\mathrm{D}=$ diâmetro médio atual da colônia;

$\mathrm{Da}=$ diâmetro médio da colônia do dia anterior;

$\mathrm{N}=$ número de dias após a inoculação

O experimento foi conduzido em blocos ao acaso, com quatro tratamentos (isolados), cada um com cinco repetições para cada uma das seis temperaturas. Foram realizados dois ensaios com o objetivo de se obter uma maior consistência dos dados. As análises estatísticas foram realizadas no programa estatístico SAEG. As variáveis significativas no teste $\mathrm{F}$ da análise de variância foram submetidas ao teste de médias e à análise de regressão. O ajuste do modelo de regressão foi realizado utilizando-se as repetições das variáveis estudadas. Avaliou-se o ajuste dos modelos linear, quadrático, exponencial, logístico e polinomial. O modelo escolhido, utilizado para plotar o gráfico, foi aquele com maior $\mathrm{R}^{2}$, menor quadrado médio dos desvios e melhor gráfico de distribuição de resíduos.

Para a determinação da produção de conídios, no sétimo dia de crescimento das culturas de $C$. gloeosporioides em meio de cultura BDA, foi feita uma suspensão, com a mesma quantidade de água por placa $(2,0 \mathrm{~mL})$ e o auxílio de uma alça de Drigalski. A partir desta suspensão, avaliaram-se 10 lâminas por placa por isolado. A contagem do número de conídios foi feita com o auxílio da câmara de Neubauer.

Quanto à porcentagem de germinação conidial, uma alíquota de $20 i \mathrm{~L}$ da suspensão dos conídios na concentração de $2 \times 10^{6} \mathrm{~mL}^{-1}$ foi colocada em microtubo de ensaio. Os microtubos foram mantidos em 
câmara de crescimento (BOD) a $20^{\circ} \mathrm{C} ; 25^{\circ} \mathrm{C} ; 28^{\circ} \mathrm{C} ; 30^{\circ} \mathrm{C} ; 32^{\circ} \mathrm{C}$ e $35^{\circ} \mathrm{C}$. Após 24 horas, procedeu-se à leitura, contando-se 100 conídios por lâmina por repetição de cada isolado, em cada temperatura. Foi considerado germinado o conídio cujo tubo germinativo apresentava $50 \%$ do tamanho do conídio.

Os dados percentuais de germinação de conídios para os quatro isolados, foram transformados em arcsen $(\sqrt{ }(($ média+0,005) /100).

Os dois ensaios realizados apresentaram resultados significativamente semelhantes em todas as avaliações realizadas. Foi observada interação significativa para o índice de velocidade do crescimento micelial (IVCM) em todas as temperaturas avaliadas. A interação isolado e temperatura não foi significativa, demonstrando não haver diferença entre isolados frente às diferentes temperaturas. Os quatro isolados apresentaram comportamento semelhante. Todos os isolados apresentaram uma única curva de regressão mostrando significância para os polinômios de terceiro e quarto graus, com $\mathrm{R}^{2}$ $=0,7302$ e $\mathrm{R}^{2}=0,9703$ respectivamente. Contudo o polinômio de quarto grau apresentou valores irreais (negativos) em pontos dentro da faixa estudada. Dessa forma os dados foram representados por um polinômio do terceiro grau, assim pôde-se estimar o máximo da velocidade de crescimento, de acordo com a curva polinomial de terceiro grau, atingido na temperatura de $24,6^{\circ}$ (Figura 1 - A).

Os isolados avaliados apresentaram em dados brutos, maior IVCM a $28^{\circ} \mathrm{C}$ seguida pela temperatura de $25^{\circ} \mathrm{C}$. Dados semelhantes foram obtidos por Dias et al.(10), que trabalhando com C. gloeosporioides isolados de frutos de cafeeiro, constataram que a temperatura ótima para o crescimento micelial está entre $22^{\circ} \mathrm{C}$ e $28^{\circ} \mathrm{C}$.

Cada fungo exige uma faixa de temperatura ideal para esporular, sendo que há fungos que reduzem sua esporulação sob baixas temperaturas e aumentam à medida que a temperatura se eleva, até atingir um ponto máximo ou o ponto ótimo para a esporulação. podendo também ocorrer o oposto.

Neste estudo, a temperatura ótima para o desenvolvimento de todos os isolados testados de C. gloeosporioides foi a de $28^{\circ} \mathrm{C}$ quando considerado os dados brutos. No entanto através do estudo da regressão observamos significância para polinômios de terceiro e quarto graus, com $\mathrm{R}^{2}=0,7408$ e $\mathrm{R}^{2}=0,9732$ respectivamente. Mesmo o polinômio de quarto grau tendo valor significativo pelo teste $\mathrm{F}$, ocorre o mesmo problema anterior, onde o mesmo apresenta valores estimados irreais (negativos) em pontos dentro da faixa estudada. Optando-se por representar os dados por um polinômio do terceiro grau, onde estimouse o máximo de crescimento, de acordo com a curva polinomial de terceiro grau na temperatura de $24,46^{\circ}$ (Figura 1-B). Estes dados corroboram com os resultados obtidos na Embrapa Semiárido em frutos de mangueira infectados por C. gloeosporioides (1).

O efeito inibidor da temperatura sobre o crescimento dos fungos é bastante variável, porém a maioria dos patógenos apresenta melhor desenvolvimento entre $20^{\circ} \mathrm{Ce} 25^{\circ} \mathrm{C}$. Varias espécies apresentam melhor desenvolvimento em temperaturas mais elevadas $(2,3)$ como é o caso do patossistema de $C$. gloeosporioides e juçara.

Tozze Junior et al. (18), estudando o crescimento de colônias de isolados de C. gloeosporioides obtidos de solanáceas, constataram que o desenvolvimento das colônias ocorreu na faixa de temperatura entre $25^{\circ} \mathrm{C}$ e $28^{\circ} \mathrm{C}$ e Vinnere (19) relata que a temperatura ótima para o crescimento micelial de $C$. gloeosporioides encontra-se entre $26^{\circ} \mathrm{Ce}$ $28,5^{\circ} \mathrm{C}$, e o crescimento é paralisado a $35,5^{\circ} \mathrm{C}$.; dados estes que corroboram com os obtidos neste estudo, visto que a melhor temperatura para o crescimento foi de $28^{\circ} \mathrm{C}$ e que a $35^{\circ} \mathrm{C}$ o crescimento dos isolados do patógeno foi completamente inibido.

Com relação a produção de conídios, todos os isolados apresentaram temperatura ótima variando entre $28^{\circ} \mathrm{C}$ e $30^{\circ} \mathrm{C}$ (Figura 2). Resultados semelhantes foram obtidos por Maia et al. (12), com isolados de C. gloeosporioides de mangueira, cuja temperatura ideal para a produção de conídios ficou entre 25 a $30{ }^{\circ} \mathrm{C}$ e por Rollemberg (15), que registrou maior produção de conídios de C. gloeosporioides a $28^{\circ} \mathrm{C}$.

A temperatura ideal para a germinação de conídios foi $28^{\circ} \mathrm{C}$ para todos os isolados (Figura 3). Maia et al. (12) verificou que a temperatura

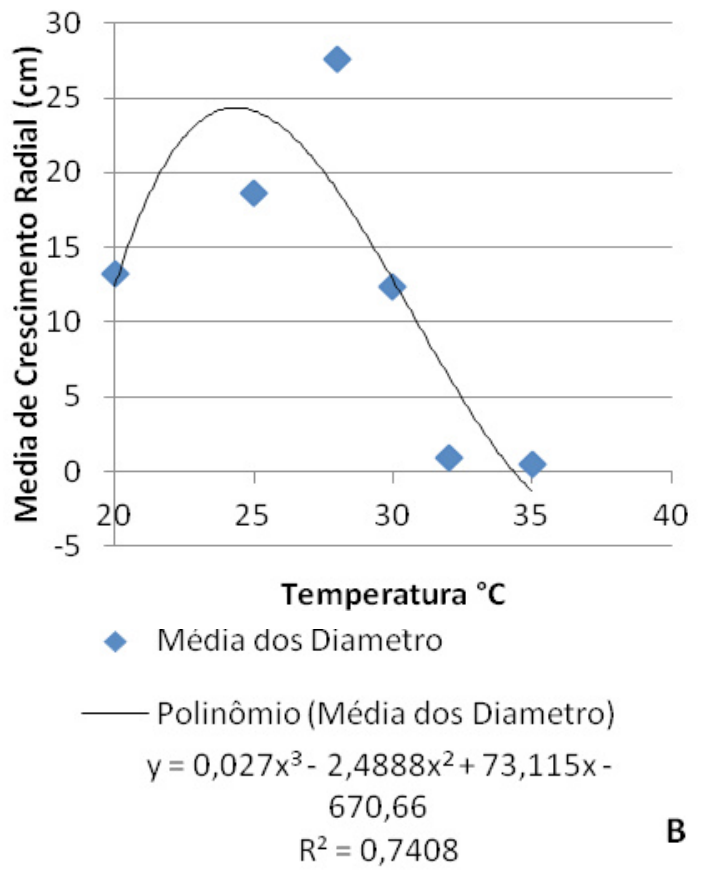

Figura 1. Regressão da média de quatro isolados de Colletotrichum gloeosporioides em diferentes temperaturas. A - Velocidade do crescimento micelial (IVCM) B - Crescimento radial 
ótima para a germinação de conídios de C. gloeosporioides foi entre $25^{\circ} \mathrm{C}$ a $30^{\circ} \mathrm{C}$. Resultados semelhantes foram obtidos por Denner et al. (9), que demostraram como a temperatura afeta a germinação dos esporos de C. gloeosporioides in vitro.

A germinação dos esporos do patógeno ocorreu na faixa de temperatura de $10^{\circ} \mathrm{C}$ a $35^{\circ} \mathrm{C}$. Vários trabalhos demonstram que temperaturas em torno de $25^{\circ} \mathrm{C}$ são ideais para a germinação de conídios de Colletotrichum sp. (15). As temperaturas ótimas para a germinação de conídios das diferentes espécies do gênero Colletotrichum variam. Goos \& Tschirsch (11) citaram a faixa de $27^{\circ} \mathrm{C}-30^{\circ} \mathrm{C}$, como ótima para a germinação de conídios de $C$. musae, enquanto que no trabalho de Cox \& Irwin (8) o intervalo é de $26^{\circ} \mathrm{C}$ a $28^{\circ} \mathrm{C}$ para a germinação de conídios do mesmo patógeno. Segundo Wilson et al. (20), a germinação de conídios de C. acutatum Simmonds, é maior na faixa entre $25^{\circ} \mathrm{C}$ e 30 ${ }^{\circ} \mathrm{C}$, em frutos de morango.
A Figura 3 ilustra a regressão polinomial do comportamento da germinação de conídios de $C$. gloeosporioides frente às diferentes temperaturas testadas. Como os quatro isolados avaliados não apresentaram diferenças significativas entre si, a germinação pode ser demonstrada por apenas uma curva para todos os isolados. Com os dados brutos, a temperatura de $28^{\circ} \mathrm{C}$ foi a melhor para a germinação. No entanto o estudo da regressão mostra significância para polinômios de terceiro e quarto graus, com $\mathrm{R}^{2}=0,9038$ e $\mathrm{R}^{2}=0,9506$ respectivamente. Neste caso, apesar do polinômio de quarto grau ter valor significativo pelo teste $\mathrm{F}$, ele apresenta valores estimados irreais (negativos) em pontos dentro da faixa estudada, além de apresentar valores também absurdos em faixas próximas à faixa estudada. Dessa forma optou-se por representar os dados por um polinômio do terceiro grau, assim pôde-se estimar o máximo de germinação, de acordo com a curva polinomial de terceiro grau que foi atingido na temperatura de

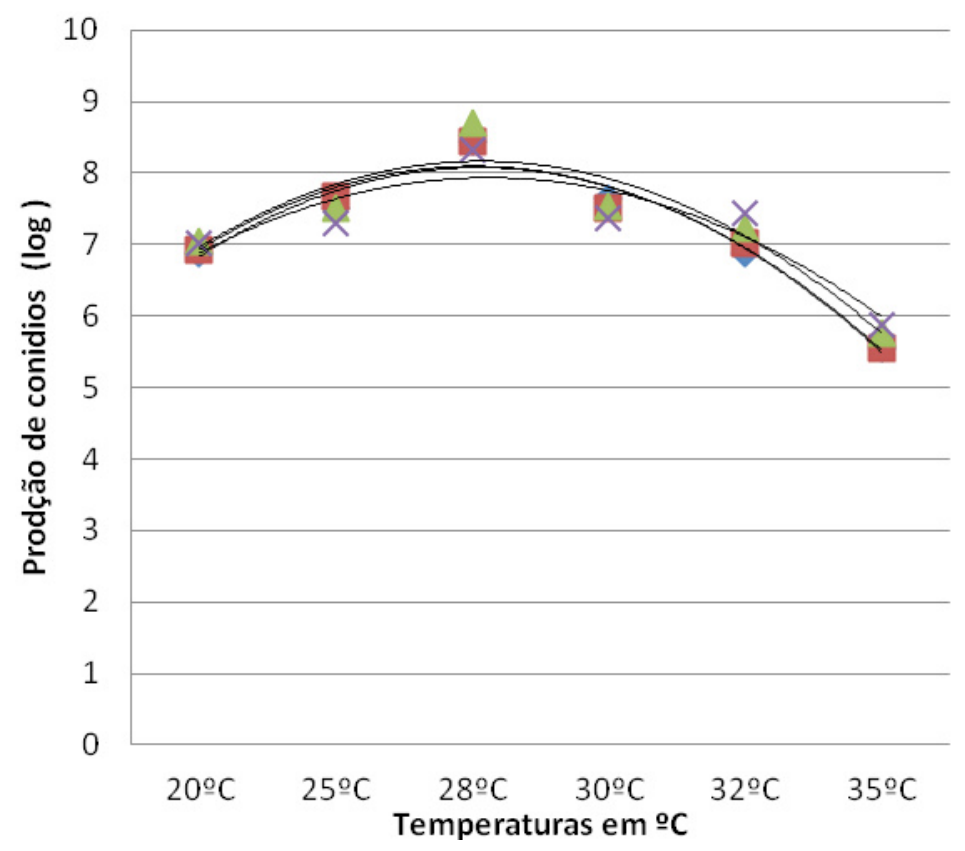

$$
\begin{gathered}
y=-0,2957 x^{2}+1,8023 x+5,3285 \\
R^{2}=0,9548 \\
y=-0,2875 x^{2}+1,7316 x+5,4852 \\
R^{2}=0,9502 \\
y=-0,2799 x^{2}+1,7184 x+5,5258 \\
R^{2}=0,8737 \\
y=-0,2339 x^{2}+1,4605 x+5,6524 \\
R^{2}=0,8241
\end{gathered}
$$

- Camburi

Corcovado

$\Delta$ Praia Almada

Praia Brava

Figura 2. Produção de conídios de isolados de Colletotrichum gloeosporioides submetidos a diferentes temperaturas

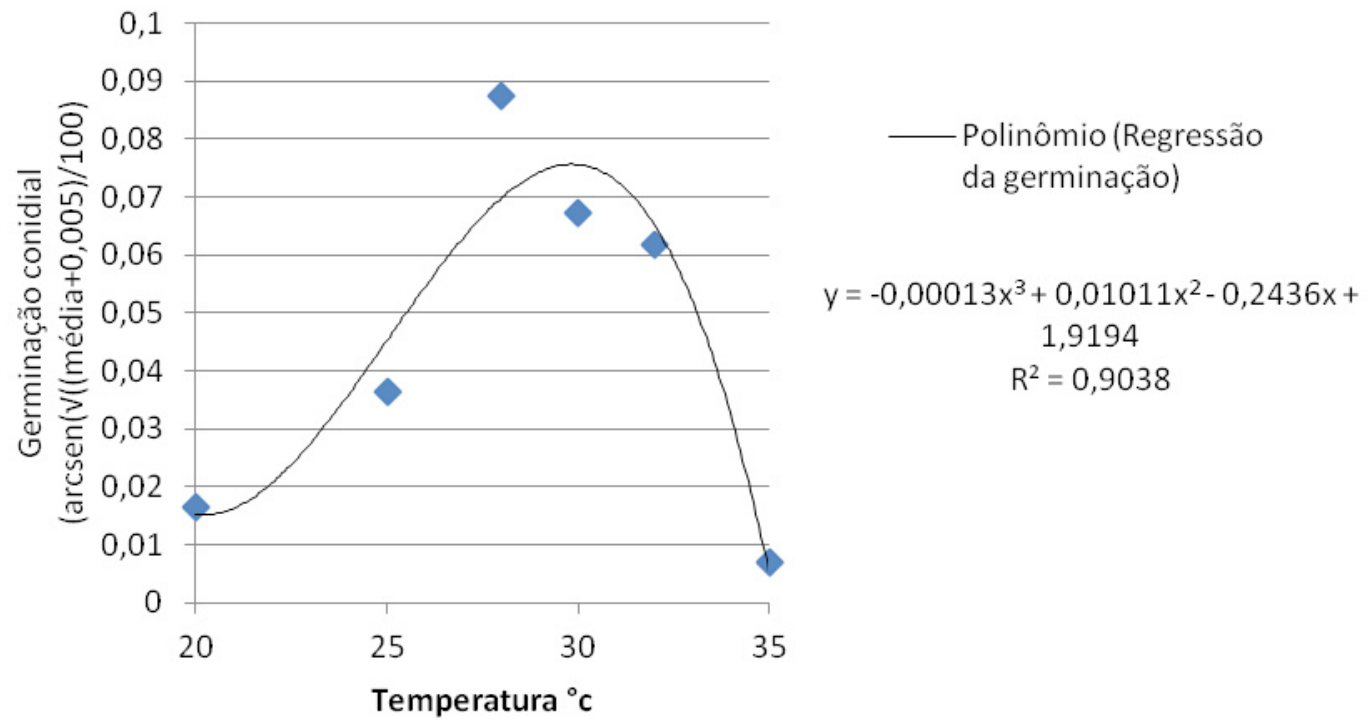

Figura 3. Regressão polinomial da germinação de Colletotrichum gloeosporioides de isolados de palmito juçara em diferentes temperaturas. 
$32,83^{\circ} \mathrm{C}$.

Conclui-se que a temperatura ideal para o desenvolvimento micelial, produção e germinação de conídios do complexo C. gloeosporioides em frutos de palmeira juçara, quando avaliado os dados brutos, é de $28^{\circ} \mathrm{C}$. Contudo ao observamos as curvas de regressão verifica-se que a temperatura ideal apresentou-se em $24,6^{\circ} \mathrm{C} ; 24,46^{\circ} \mathrm{C}$ e $32,82^{\circ} \mathrm{C}$ para o IVCM, desenvolvimento micelial, produção e germinação de conídios respectivamente.

Quanto aos isolados, a Praia Almada demonstrou-se mais agressiva seguida de Corcovado, Camburi e praia Brava respectivamente, ao avaliar o crescimento micelial, enquanto que em relação ao número de conídios e a germinação não foi verificada diferença significativa entre eles.

\section{REFERÊNCIAS BIBLIOGRÁFICAS}

1. Batista, D. da C. Cultivo da mangueira: doenças. 2. ed. Embrapa Semiárido (Sistemas de Produção, 2) Disponível em: <http:// sistemasdeproducao.cnptia.embrapa.br/FontesHTML/Manga/ CultivodaMangueira_2ed/doencas.htm> . Acesso em 13. Jun. 2012.

2. Benato, E.A. Controle de doenças pós-colheita em frutas tropicais. Summa Phytopathologica, Piracicaba, v.25, n.1, p.9093, 1999.

3. Benato, E.A.; Cia, P.; Souza, N.L. Manejo de doenças de frutos pós-colheita. Revisão anual de patologia de plantas, Passo Fundo, v.9, p.403-440, 2001.

4. Cardoso, LM.C.; Leite, J.P.V. Palmeira juçara: A esxploração dos frutos é mais ecológica e rentável do que a do Palmito, Espaço do Produtor, Universidade Federal de Viçosa, 2009. Disponível em: $<$ https://www2.cead.ufv.br/espacoProdutor/scripts/ver Artigo.php?codigo=19\&acao=exibir $>$ Acesso em: 20 mai. 2012

5. Centro de Pesquisas Meteorológicas e Climáticas Aplicadas a Agricultura, Média climática no município de Ubatuba, Campinas, 2012. Disponivel em: <http://www.cpa.unicamp.br/outrasinformacoes/clima_muni_624.html>. Acesso em: 16. mar. 2012.

6. Centro de Previsão de Tempo e Estudos Climáticos. Média climática no município de Paraty, Disponível em: <http:// clima1.cptec.inpe.br/>. Acesso em: 16. mai. 2012.

7. Costa, E.A.D.; Corbellini, L.M.; Reis, C.S.; Santos, A.S.; Cheraulti, V.J.; Silva, M. B. M. Produção de polpa e sementes dos frutos de Euterpe edulis - Uma alternativa de geração de renda e uso sustentável da mata Atlântica. Ubatuba, Instituto de Permacultura e Ecovilas da Mata Atlântica, São Paulo, 2006.

8. Cox, M.L.; Irwin, J.A.G. Conidium and apressorium variation in Australian isolates of the Colletotrichum gloeosporioides group and closely related species. Australian Systematic Botany, Collingwood, v.1, p.139-144. 1988.

9. Denner, F.D.N.; Kotzé J.M.; Putterill J.F. The effect of tempera- ture on spore germination, growth and appressorium formation of Colletotrichum gloeosporioides and Dothiorella aromatica. South African Avocado Growers Association Yearbook, v.9 p. 19-22, 1986 .

10. Dias, M.D.; Pozza, E.A.; Abreu, M.S. de; Miranda, E.O. Efeito da temperatura no crescimento micelial, produção e germinação de conídios de Colletotrichum spp. isolados de Coffea arabica L. Ciência e Agrotecnologia, Lavras, v.29, n.3, p.545-552, 2005.

11. Goos, R.D.; Tschirsch, M. Effect of environmental factors on spore germination, spore survival, and growth of Gloeosporium musarum. Mycologia, Lawrence, v.54, p.353-367, 1962.

12. Maia, F.G.M.; Armesto, C.; Zancan, W.L.A.; Maia, J.B.; Abreu, M.S. Efeito da temperatura no crescimento micelial, produção e germinação de conídios de Colletotrichum spp. isolados de mangueira com sintomas de antracnose. Bioscience Journal, Uberlândia, v.27, n.2, p.205-210, 2011.

13. Oliveira, J.A. Efeito do tombamento fungicida em sementes no controle de tombamento de plântulas de pepino ( $\mathrm{Cucu}$ mis sativas L.) e pimentão (Capsicum annanum L.). 1991. 111 f. Dissertação (Mestrado em Fitossanidade) - Escola Superior de Agricultura de Lavras, Lavras.

14. Reis, D.C.; Azevedo, L.A.S. Manejo dos frutos da palmeira juçara (Euterpe edulis) para obtenção de polpa como uma alternativa de renda para comunidades caiçaras no município de Ubatuba, SP. In: Simpósio de Pesquisa em Mata Atlântica, Engenheiro Paulo de Frontin,1., 2010, Rio de Janeiro. Resumos Rio de Janeiro: Instituto Zoobotânico de Morro Azul, 2010. p.33.

15. Rollemberg, C. de L. Mancha das folhas da macieira: caracterização fisiológica dos agentes causais, controle biológico com bactérias residentes de filoplano e sensibilidade dos antagonistas a fungicidas e inseticidas. 2008. 124f. Dissertação (Mestrado em Agronomia) - Universidade Federal do Paraná, Curitiba.

16. Silva, M.G.C.P.C.; Barretto, W.S.; Serôdio, M.H. Comparação nutricional da polpa dos frutos de juçara e de açaí. Ilhéus: Centro de Pasquisa do Cacau, Ministério da Agricultura, Agropecuária e Abastecimento, 2004. Disponível em: <http://www.ceplac.gov.br/ index.asp>. Acesso em: 25. maio. 2012.

17. Soares, A.R; Lourenço, S.A; Amorim, L. Infecção de goiabas por Colletotrichum gloeosporioides e Colletotrichum acutatum sob diferentes temperturas e periodo de molhamento. Tropical Plant Patology, Brasília, v.33, n.4, p.265- 272, 2008.

18. Tozze Junior, H.J.; Mello, B.A.; Massola-Junior, N.S. Caracterização morfológica e fisiológica de isolados de Colletotrichum sp. causadores de antracnose em solanaceas. Summa Phytopathologica, Botucatu, v.32, n.1, p.77-79, 2006.

19. Vinnere, O. Aproaches to species delineation in anamorphic (mitosporic) fungi: A study on two extreme cases. Comprehensive Summaries of Uppsala Dissertations from the Faculty of Science ad Technology, Uppsala, v.917, p.72, 2004.

20. Wilson, L.L.; Madden, L.V.; Ellis, M.A. Influence of temperature and wetness duration on infection of immature and mature strawberry fruit by Colletotrichum acutatum. Phytopathology, St. Paul, v.80, p.111-116, 1990. 